\title{
Adsorption of cadmium ions from aqueous solutions using sesame as a low-cost biosorbent: kinetics and equilibrium studies
}

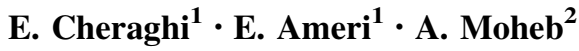

Received: 17 June 2014/Revised: 23 February 2015/Accepted: 18 April 2015/Published online: 1 May 2015

(C) Islamic Azad University (IAU) 2015

\begin{abstract}
Sesame leaf and stem, as a kind of useless agricultural waste, was used as a sort of low-cost biosorbent for the removal of cadmium ions from aqueous solutions in batch and continuous modes. The biomass was characterized by Fourier transform infrared spectroscopy, scanning electron microscope and energy-dispersive X-ray analysis before and after adsorption. There were hydroxyl group, carboxyl group, etc. on the surface of the adsorbent from Fourier transform infrared spectroscopy. A batch study was employed as a function of the initial concentration, adsorbent particle size, adsorbent dose, contact time and the $\mathrm{pH}$ of the solution. Maximum sorption was found to occur at an initial $\mathrm{pH}$ of 6 . The equilibrium process was satisfactorily described by the Langmuir isotherm model with the maximum sorption capacity of $84.74 \mathrm{mg} \mathrm{g}^{-1}$. Kinetic studies also indicated that both pseudo-first-order and pseudo-second-order kinetic models (with $R^{2}$ values of 0.9929 and 0.9952 , respectively) were able to describe the process. A continuous study was carried out, and the maximum uptake of cadmium ions in a fixed-bed adsorption column was found to be $22.88 \mathrm{mg} \mathrm{g}^{-1}$, where the initial concentration of cadmium ions, bed height, flow rate and $\mathrm{pH}$ were $60 \mathrm{mg} \mathrm{L}^{-1}, 2 \mathrm{~cm}$, $2.5 \mathrm{~mL} \mathrm{~min}^{-1}$ and 5.5, respectively.
\end{abstract}

E. Ameri

ameri@iaush.ac.ir

1 Department of Chemical Engineering, Shahreza Branch, Islamic Azad University, P.O. Box 311-86145, Shahreza, Isfahan, Iran

2 Department of Chemical Engineering, Isfahan University of Technology, 84156-83111 Isfahan, Iran
Keywords Agricultural waste $\cdot$ Biosorption $\cdot$ Heavy metals $\cdot$ Isotherm $\cdot$ Water treatment

\section{Introduction}

Biosorption, as an alternate method, is becoming one of the most effective methods for the elimination of heavy metals from wastewater. The main advantages of biosorption over the conventional treatment methods include high efficiency, low cost, minimization of chemical or biological sludge, regeneration of biosorbents and the possibility of metal recovery. The mechanisms of biosorption process contain chemisorption, complexation, adsorption on surface, diffusion through pores, ion exchange, etc. Metal ion biosorption can be happen according to an electrostatic attraction between metal cations and negatively charged sites on the biosorbent surface such as, carboxyl, phosphoryl, phosphate, amino, amido, acetamido, sulfate and hydroxyl groups (Tunali et al. 2006). Various plant-andmicroorganism-derived materials such as yeast (Volesky et al. 1993), inactivated bacteria (Chang et al. 1997), sawdust (Shukla et al. 2002) and other agricultural wastes (Chowdhury and Saha 2012), fungus (Tunali et al. 2006), algae (Vilar et al. 2006) and aquatic plants and seaweed (Mohanty et al. 2006) have been investigated as biosorbents.

Agricultural wastes, which can be highly efficient, inexpensive and renewable sources of biomass, can be used for heavy metal removal. In this regard, the adsorption properties of copper ion and methylene blue onto the citric acid-modified wheat straw have been studied in single adsorbate system by batch techniques (Han et al. 2010). Nameni et al. investigated the chromium adsorption from aqueous solutions by wheat bran; they studied the effect of 
different parameters on the adsorption process (Nameni et al. 2008). The adsorption of copper and chromium was investigated by the residue of brewed tea from aqueous solutions, and it was shown that adsorbent dose, and copper and chromium ion concentrations, in such solutions influenced the degree of obviation of these heavy metal ions (Dizadji and Abootalebi 2011). Recently, Kamsonlian et al. evaluated the effectiveness of some biomass prepared from mango leaf powder and rice husk to remove As(III) from aqueous solutions (Kamsonlian et al. 2012). The batch removal of hexavelant chromium from aqueous solutions using almond shell, activated sawdust and activated carbon under different experimental conditions was investigated (Aliabadi et al. 2012). The adsorption behavior of some low-cost adsorbents such as peanut husk charcoal, fly ash and natural zeolite, with respect to $\mathrm{Cu}$ (II) and $\mathrm{Zn}$ (II) ions, has been also investigated in order to address the purification of metal finishing wastewater (Abdel Salam et al. 2011). Moreover, the ability of modified soda lignin extracted from oil palm empty fruit bunches in removing lead(II) ions from aqueous solutions has been explored (Ibrahim et al. 2010). The potential use of rice bran and wheat bran for the removal of cadmium has also been reported (Montanher et al. 2005; Singh et al. 2005).

Rice polish, rice husk and black gram husk, in their natural form as well as modified forms, were utilized for separating cadmium ions, and their relative efficiencies were determined (Kumar and Bandyopadhyay 2006; Singh et al. 2005). Plant biomass of parthenium was also tried for the biosorption of cadmium (Ajmal et al. 2006). Adsorption experiments conducted on other parts of some plants such as peels of peas, fig leaves, broad beans, orange peels, medlar peels and jack fruits as adsorbents showed high removal efficiencies at acidic $\mathrm{pH}$ (Benaissa 2006). High removal efficiencies for the removal of cadmium have also been reported by using hazelnut shells, peanut hulls, walnut shells and green coconut shells (Kurniawan et al. 2006). Biosorption equilibrium and kinetics of $\mathrm{Cd}$ (II) and $\mathrm{Cu}$ (II) ions in the case of wheat straw have been studied. Also, there have been kinetics and equilibrium studies of $\mathrm{Pb}$ (II) and $\mathrm{Cd}$ (II) removal onto colemanite ore waste in aqueous systems. The removal percentage of metal ions onto wheat straw was found to be $87 \%$ at equilibrium time, and the adsorption capacity of colemanite ore waste was found to be 33.6 and $29.7 \mathrm{mg} \mathrm{g}^{-1}$ for $\mathrm{Pb}$ (II) and $\mathrm{Cd}$ (II) ions, respectively (Dang et al. 2009; Sari and Tuzen 2009).

Also, some studies focused on the activated carbon of bagasse pith, coir pith, peanut shells and dates. In these cases, the removal efficiencies for cadmium varied from 50 to $98 \%$ (Kadirvelu et al. 2001; Kannan and Rengasamy 2005). Moreover, carbons derived from tire and char wastes were reported to be the potential adsorbents for the removal of organic and inorganic pollutants from wastewaters (Hou et al. 2013; Saleh and Gupta 2014). More recently, Al-Saadi et al. studied the utilization of waste tire carbons as a low-cost adsorbent for the removal of $\mathrm{Cd}(\mathrm{II})$ from aqueous solutions with density functional theory calculations to shed more light on the adsorption process. They showed that the activated carbon could be an effective adsorbent for the removal of $\mathrm{Cd}(\mathrm{II})$ from aqueous solutions (Al-Saadi et al. 2013).

Also, nanomaterials can be used as adsorbents to remove metal ions and dyes (Gupta et al. 2011a, b; Saleh 2011; Saleh and Gupta 2012; Gupta et al. 2013; Gupta and Saleh 2013). In this regard, $\mathrm{Fe}_{3} \mathrm{O}_{4}$ nanoadsorbents have been employed for the removal of lead from aqueous solutions by a batch adsorption technique (Nassar 2010). In another study, an agricultural waste-orange peel powder was successfully modified into a novel magnetic nanoadsorbent by co-precipitating it with $\mathrm{Fe}_{3} \mathrm{O}_{4}$ nanoparticles for cadmium ion removal from aqueous solutions (Gupta and Nayak 2012). Alumina-coated multiwall carbon nanotubes were synthesized and used as an adsorbent for the lead removal from aqueous solutions in two modes, batch and fixed bed (Gupta et al. 2011c). Also, multiwall carbon nanotubes (MWCNTs) and the $\mathrm{MWCNT} / \mathrm{MnO}_{2}$ composite were examined for $\mathrm{As}(\mathrm{III})$ and $\mathrm{As}(\mathrm{V})$, in batch culture experiments (Saleh et al. 2011).

Most investigations have shown that agricultural wastes, in natural or modified forms, are significantly effectual for the biosorption of cadmium metal ions. In this regard, sesame is widely cultured, usually as a source of oil. The production and use of sesame oil have been established in Iran for more than 4000 years. It is also highly appreciated by farmers as a second crop after harvesting cereal, and the increasing use of oil extracted from this plant in the industry has enhanced the demand for its acreage. However, sesame leaf and stem is an abundant agricultural by-product which is arbitrary discarded. This useless sesame residue (leaf and stem) is burnt, thereby causing environmental pollution. Therefore, it not only is wasteful, but also pollutes the environment. In addition, sesame leaf and stem, like other plant materials containing plentiful amounts of floristic fibers made of cellulose, hemicellulose and lignin, may be an appropriate candidate as an economical potential biosorbent (Allouche et al. 2011). On the other hand, from the literature reviewed above, only two 
biosorption studies have reported the use of sesame as a biosorbent for the removal of $\mathrm{pb}^{2+}$ (Surchi 2011). The results have shown that sesame waste can be considered as a promising biosorbent for $\mathrm{pb}^{2+}$ removal. Hence, in this work, the capability of this locally available agricultural waste for the removal of cadmium ions from aqueous solutions was investigated for the first time.

During the batch experiments, the effects of different operational parameters such as the initial concentration of feed solution, adsorbent particle size, adsorbent dose, contact time and $\mathrm{pH}$ of solution were investigated. Moreover, to test the biosorption capability of the sesame waste for practical applications, column study was also carried out. This work was conducted at the College of Engineering, Shahreza Branch, Islamic Azad University, Isfahan, Iran, from October 2013 to April 2014.

\section{Materials and methods}

\section{Preparation and characterization of the adsorbent}

Sesame waste was collected from a local industry center located in Shiraz, Iran. This waste contained stem and leaf parts of the sesame. This raw material was first soaked and washed thoroughly with distilled water to remove any dirt. It was then dried in an oven at $110{ }^{\circ} \mathrm{C}$ until it reached a constant weight. Then, it was cut into uniform lengths of $1 \mathrm{~cm}$ and fed to a mixer and grinder and thus ground. Finally, it was sieved to separate the particles which were in the range of $0.15-2 \mathrm{~mm}$. The prepared samples with different mesh sizes were kept in self-sealing plastic pockets and taken for the biosorption experiments. The functional groups presented in the sesame were characterized by a Fourier transform infrared (FTIR) spectrometer (PE-1710, USA) using potassium bromide disks to prepare the sesame sample. The spectral range varied from 4000 to $400 \mathrm{~cm}^{-1}$. Scanning electron microscopic (SEM-Stereo Scan LEO, Model-400) and electron-dispersive X-ray analyses (TESCAN, USA) were performed to determine the surface characteristics of the sesame biosorbents. It is worth noting that to recognize the adsorbed Cd(II) ions onto the sesame waste, the FTIR, SEM and EDX analyses were performed at two conditions for the biosorbent: before and after the biosorption process. Also, desorption and reusability studies of the biomass were conducted.

Moreover, zero point charge $\left(\mathrm{pH}_{\mathrm{pzc}}\right)$ was estimated for the biosorbent. $\mathrm{pH}_{\mathrm{pzc}}$ is the main property that specifies the electrical neutrality of the biosorbent at a particular value of $\mathrm{pH}$. The graph of $\mathrm{pH}_{\text {intial }} \mathrm{vs}_{\mathrm{pH}}$ final was plotted, and the intersection of the curve with the straight line having the slope of $45^{\circ}$ was identified as the end point of the $\mathrm{pH}_{\mathrm{pzc}}$ (Sharma et al. 2009a, b). Finally, in order to investigate the effect of ions presented in the adsorption media, the leaching tests of the biomass were performed.

\section{Reagents}

$\mathrm{Cd}\left(\mathrm{NO}_{3}\right)_{2} \cdot 4 \mathrm{H}_{2} \mathrm{O}$ was used as the source of metal ions. All other chemicals used, such as $\mathrm{HCl}$ and $\mathrm{NaOH}$, were of analytical reagent grade and supplied by Merck. Deionized water was used throughout the experiments for preparing aqueous solutions.

\section{The general procedure for biosorption studies}

\section{Batch experiments}

All experiments were performed at room temperature, i.e., $25 \pm 1{ }^{\circ} \mathrm{C}$. A stock solution containing $1000 \mathrm{mg} \mathrm{L}^{-1}$ $\mathrm{Cd}(\mathrm{II})$ ions was prepared by dissolving a proper amount of $\mathrm{Cd}\left(\mathrm{NO}_{3}\right)_{2} \cdot 4 \mathrm{H}_{2} \mathrm{O}$ in deionized water and subsequently diluting it to the required concentrations, closely prior to their use. The biosorption of $\mathrm{Cd}(\mathrm{II})$ ions on sesame was studied by the batch technique. The general method for this purpose is as follows. The required amount of sesame was equilibrated with $30 \mathrm{ml}$ aqueous solution of adsorbate $\mathrm{Cd}\left(\mathrm{NO}_{3}\right)_{2} \cdot 4 \mathrm{H}_{2} \mathrm{O}$ at a specific initial concentration (2$100 \mathrm{mg} \mathrm{L}^{-1}$ ) in $50-\mathrm{mL}$ beakers on a shaker (IKA KS130Basic). The initial $\mathrm{pH}$ of the feed solutions was adjusted at the desired values by adding diluted $\mathrm{HCl}$ or $\mathrm{NaOH}$ solutions, using a Radwag model AS 220/C/2 pH meter. According to the results obtained from some preliminary experiments, all empirical studies were performed at the agitation speed with the optimized value of $240 \mathrm{rpm}$. The time needed for reaching the equilibrium condition was determined by keeping samples at regular intervals of time till equilibrium was achieved. After the completion of predetermined time intervals, the content of the beakers was separated by high-speed centrifugation at $4000 \mathrm{rpm}$ (Nuve NF200). The probable remaining biosorbent in solution was removed by filter paper (Wattman 40). Finally, the concentration of $\mathrm{Cd}(\mathrm{II})$ ions in the filtrate was measured by a flame atomic absorption spectrophotometer, PerkinElmer (USA, Aanalist 2300). Air-acetylene flame and Hollow Fiber Cathode as the light source with the linear 
range of $2 \mathrm{ppm}$ were used for the evaluation of $\mathrm{Cd}(\mathrm{II})$ concentration by atomic absorption. Also, the working conditions such as wavelength and slit width were $228.8 \mathrm{~nm}$ and $0.7 \mathrm{~nm}$, respectively. All experiments were repeated in triplicate. The equilibrium adsorption capacity, $Q_{\mathrm{e}}$, of $\mathrm{Cd}(\mathrm{II})$ and the percent removal of $\mathrm{Cd}(\mathrm{II})$ were calculated using the following equations, respectively:

$Q_{\mathrm{e}}=\frac{V\left(C_{\mathrm{o}}-C_{\mathrm{e}}\right)}{m}$

$\%$ Removal $=\frac{\left(C_{\mathrm{o}}-C_{\mathrm{e}}\right)}{C_{\mathrm{o}}} \times 100$

where $V$ is the sample volume (L), $m$ is the mass of biosorbent $(\mathrm{g}), C_{\mathrm{o}}$ is the initial concentration of $\mathrm{Cd}(\mathrm{II})$ in the solution $\left(\mathrm{mg} \mathrm{L}^{-1}\right)$ and $C_{\mathrm{e}}$ is the equilibrium concentration of $\mathrm{Cd}(\mathrm{II})$ in the solution $\left(\mathrm{mg} \mathrm{L}^{-1}\right)$. For time-dependent data, $C$ and $Q$ substitute $C_{\mathrm{e}}$ and $Q_{\mathrm{e}}$ in Eq. (1), respectively.

The effect of adsorbent dosage level on the percent removal of cadmium was investigated using a $\mathrm{Cd}(\mathrm{II})$ concentration of $20 \mathrm{mg} \mathrm{L}^{-1}$ having a $\mathrm{pH}$ adjusted to 6 . The adsorbent was used at concentrations ranging from 1.67 to $100 \mathrm{~g} \mathrm{dm}^{-3}$. Adsorption experiments that were employed to investigate the effect of $\mathrm{pH}(2-9)$ were carried out using a solution having $20 \mathrm{mg} \mathrm{L}^{-1}$ of $\mathrm{Cd}(\mathrm{II})$ concentration with an adsorbent dosage of $3.33 \mathrm{~g} \mathrm{dm}^{-3}$ and stirring the same solution for a contact time of $30 \mathrm{~min}$. The effects on the variation of initial concentration $\left(2-100 \mathrm{mg} \mathrm{L}^{-1}\right)$ and adsorbent size $(0.15-2 \mathrm{~mm})$ were investigated using $\mathrm{Cd}$ (II) solution of concentration at the $\mathrm{pH} 5.5$, the contact time of $30 \mathrm{~min}$ and the adsorbent dosage level of $3.33 \mathrm{~g} \mathrm{dm}^{-3}$.

In order to calculate the adsorption capacity of sesame, the experimental data were fitted to the Langmuir and Freundlich isotherm models, which are generally used in describing adsorption processes. Adsorption isotherm investigations were conducted with different initial concentrations of $\mathrm{Cd}(\mathrm{II})$, from 2 to $1000 \mathrm{mg} \mathrm{L}^{-1}$ at $\mathrm{pH} 5.5$, the contact time $30 \mathrm{~min}$ and the adsorbent dosage level of $3.33 \mathrm{~g} \mathrm{dm}^{-3}$. The determination coefficient, $R^{2}$, was utilized to estimate the agreement of the experimental data with the model. The coefficient of determination can be written as shown below:

$R^{2}=\frac{\sum_{1}^{n}\left(y_{\mathrm{mod}}-y_{\mathrm{ave}}\right)^{2}}{\left[\sum_{1}^{n}\left(y_{\mathrm{mod}}-y_{\mathrm{ave}}\right)^{2}+\sum_{1}^{n}\left(y_{\mathrm{exp}}-y_{\mathrm{mod}}\right)^{2}\right]}$

where $n$ is the number of data points and $y_{\bmod }, y_{\mathrm{avg}}$ and $y_{\exp }$ are the predicted values from the linear model, the averaged value of the experimental data points and the individual experimental data points, respectively.

The kinetic studies were conducted by considering the first-order and second-order kinetic models. The kinetic parameters for the adsorption process were investigated on the batch adsorption of $20 \mathrm{mg} \mathrm{L}^{-1}$ of $\mathrm{Cd}(\mathrm{II})$ at $\mathrm{pH} 5.5$ and the adsorbent dosage level of $3.33 \mathrm{~g} \mathrm{dm}^{-3}$.

\section{Continuous experiments}

Batch biosorption study provided fundamental information related to the cadmium biosorption performance for sesame waste biosorbent. However, for practical application, a continuous mode of operation was preferred. So, continuous biosorption experiments were performed too. Continuous experiments were carried out in a laboratoryscale glass column with the internal diameter of $2.2 \mathrm{~cm}$ and the length of $30 \mathrm{~cm} .4 .00 \mathrm{~g}$ of sesame (equivalent to $2 \mathrm{~cm}$ of bed depth) with the particle size of $0.21 \mathrm{~mm}$ was packed in the column between glass wool, which prevented the sesame waste from being washed out and enabled a uniform inlet flow into the column. According to the results obtained from some preliminary experiments, the column study was performed at optimum experimental conditions of the influent $\mathrm{Cd}(\mathrm{II})$ concentration of $60 \mathrm{mg} \mathrm{L}^{-1}$, the flow rate of $2.5 \mathrm{~mL} / \mathrm{min}$ and the $\mathrm{pH}$ of 5.5 at $298 \mathrm{~K}$. Effluent samples were collected during the time course of the experiments to determine the metal concentration in the effluent solutions. Then, they were analyzed by atomic absorption spectrometry (PerkinElmer model Aanalist 2300). The flow to the column was continued until the $\mathrm{Cd}(\mathrm{II})$ concentration was close to the influent concentration.

The value of the total mass of metal adsorbed, $Q_{t}(\mathrm{mg})$, can be determined from the following equation (Han et al. 2009):

$Q_{t}=\frac{Q}{1000} \int_{t: 0}^{t: t_{t}} C_{\mathrm{ad}} \mathrm{d} t$

where $C_{\text {ad }}$ refers to the concentration of metal removal $\left(\mathrm{mg} \mathrm{L}^{-1}\right)$.

Maximum capacity of the column, $Q_{\max }\left(\mathrm{mg} \mathrm{g}^{-1}\right)$, can be determined from the following equation:

$Q_{\max }=\frac{Q_{t}}{m}$

where $m$ expresses the dry weight of the adsorbent in the column $(\mathrm{g})$. The total value of metal ion sent to the column $\left(m_{t}\right)$ is evaluated as follows (Oguz and Ersoy 2010): 
$m_{t}=\frac{C_{0} Q_{t} t}{1000}$

where $C_{0}$ is the inlet metal ion concentration $\left(\mathrm{mg} \mathrm{L}^{-1}\right)$. At last, the removal percentage of $\mathrm{Cd}(\mathrm{II})$ ions can be achieved from the following equation:

$\%$ Removal $=\frac{Q_{t}}{m_{t}} \times 100$

\section{Desorption and reusability studies}

Desorption studies were performed in $20 \mathrm{~mL}$ of $0.5 \mathrm{M}$ $\mathrm{HNO}_{3}$ maintained at a constant temperature of $298 \mathrm{~K}$. The $\mathrm{Cd}(\mathrm{II})$-adsorbed sesame waste was placed in the desorbing medium on a rotary shaker at $240 \mathrm{rpm}$ for $30 \mathrm{~min}$. In order to evaluate the amount of cadmium ions desorbed, analyte contents of the final solution were analyzed by flame atomic absorption spectrometry. The percentage of the desorption of $\mathrm{Cd}$ (II) ions was calculated from the following expression:

\%Desorption $=\left(m_{\mathrm{r}} / m_{0}\right) \times 100$

where $m_{\mathrm{r}}$ is the amount of cadmium ions desorbed $(\mathrm{mg})$ and $m_{0}$ is the amount of cadmium ions adsorbed (mg).

Reusability study of sesame waste was performed by following the adsorption-desorption study for four cycles. The adsorption efficiency in each cycle was evaluated.

\section{Results and discussion}

\section{Characterization of the biosorbents}

\section{Scanning electron microscopy (SEM)}

Scanning electron micrographs of sesame particles before and after cadmium uptake are shown in Fig. 1a, b.

The micrographs showed that the biosorbent had a rough and irregular surface providing a large area for ion-surface interaction (Fig. 1a). A significant change in the biosorbent surface was observed after the biosorption of cadmium (Fig. 1b). A polishing/smoothening effect perceived in Fig. 1b is not observed in Fig. 1a. This may be due to the fact that the adsorption of cadmium ions over biosorbent makes the surface of biosorbent smoother than its original form. Moreover, the pores with a channel shape existing in the biosorbent surface had been covered with the cadmium ions during the biosorption process, leading to the smoothness of the internal surface of the channels (Cheraghi et al. 2015).

\section{Energy-dispersive X-ray (EDX) analysis}

Figure 1c, d shows the typical EDX patterns for sesame waste, before and after the sorption of Cd(II). The EDX pattern (Fig. 1c) for the unloaded sesame waste did not display the characteristic signal of $\mathrm{Cd}(\mathrm{II})$, whereas for the Cd(II)-loaded sesame waste (Fig. 1d), a signal of the presence of $\mathrm{Cd}(\mathrm{II})$ was observed. Besides, the presence of $\mathrm{Mg}^{2+}, \mathrm{Ca}^{2+}$ and $\mathrm{K}^{+}$which were shown to be involved in the ion exchange with $\mathrm{Cd}(\mathrm{II})$ was observed in the spectra of the unloaded sesame waste.

After the adsorption of the Cd(II) onto sesame waste, however, $\mathrm{Ca}^{2+}$ and $\mathrm{K}^{+}$cations were observed with no or less intensity in the EDX spectrum of $\mathrm{Cd}(\mathrm{II})$-loaded biosorbent. These findings, as related EDX analysis, showed the involvement of ion exchange mechanism in the removal of metal ions by sesame waste.

\section{Fourier transform infrared analysis of the biosorbent}

To determine the type of the functional groups effective for $\mathrm{Cd}(\mathrm{II})$ ions removal, FTIR spectra of the adsorbent, before and after $\mathrm{Cd}(\mathrm{II})$ ions removal, were obtained as shown in Fig. 1e, f. The spectra of the biosorbent were measured in the wave number range of $400-4000 \mathrm{~cm}^{-1}$.

The FTIR spectrum of sesame waste showed a broad peak at $3298 \mathrm{~cm}^{-1}$ which was related to the $\mathrm{O}-\mathrm{H}$ stretching vibrations of cellulose, pectin, hemicellulose and lignin (Feng et al. 2009). The $\mathrm{OH}$ stretching vibrations took place within a broad range of frequencies, representing the existence of free hydroxyl groups and bonded $\mathrm{OH}$ bands of carboxylic acids (Namasivayam and Kavitha 2006). The bands at 2924 and $2854 \mathrm{~cm}^{-1}$ were indicative of the stretching vibration of $-\mathrm{CH}_{3}$ and $-\mathrm{CH}_{2}$, respectively. The strong peak near $1658 \mathrm{~cm}^{-1}$ could be assigned to stretch vibration of $\mathrm{C}-\mathrm{O}$ from carboxyl group in the presence of intermolecular hydrogen bonding. The peak around $1541 \mathrm{~cm}^{-1}$ could also be attributed to the presence of the $\mathrm{C}-\mathrm{C}$ stretching of aromatic ring (Han et al. 2010). The peak at $1431 \mathrm{~cm}^{-1}$ was characteristic of the symmetric bending of $-\mathrm{CH}_{3}$. The strong peak perceived at $1054 \mathrm{~cm}^{-1}$ presented the vibration of $\mathrm{C}-\mathrm{O}$ and stretching vibration in the lignin structure of the sesame. The band around $1245 \mathrm{~cm}^{-1}$ could also be attributed to the presence of the $\mathrm{C}-\mathrm{O}$ 
(a)

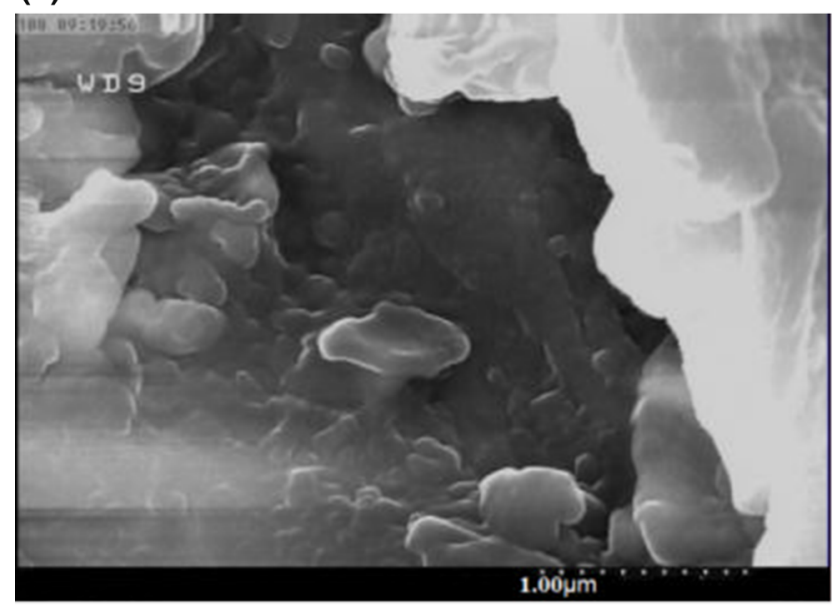

(c)

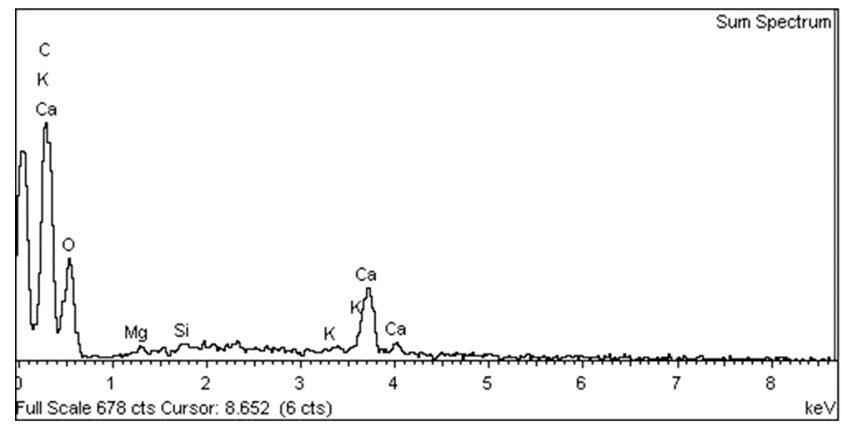

(e)

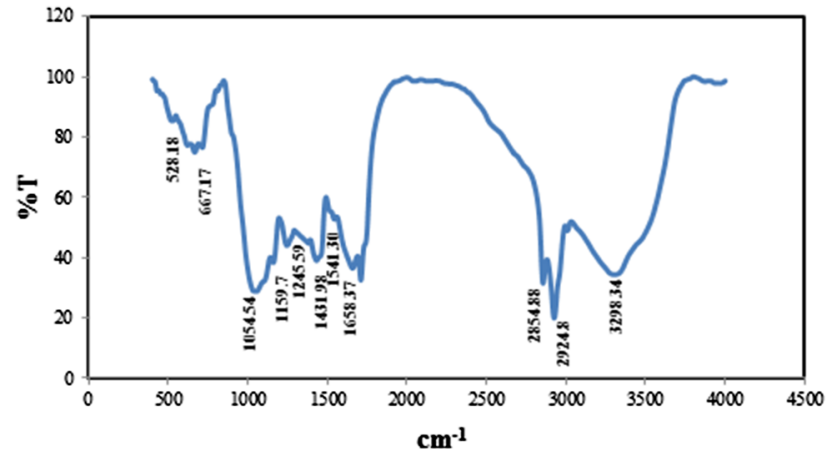

(b)

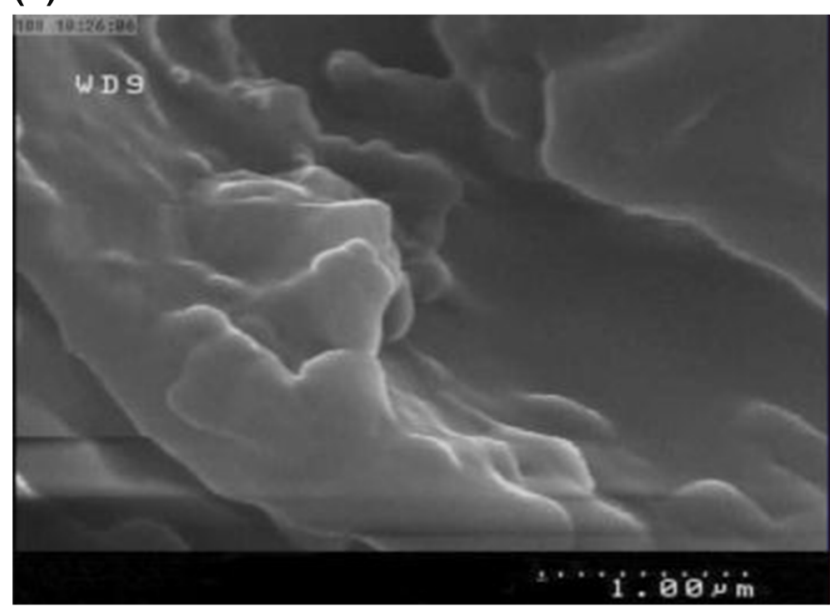

(d)

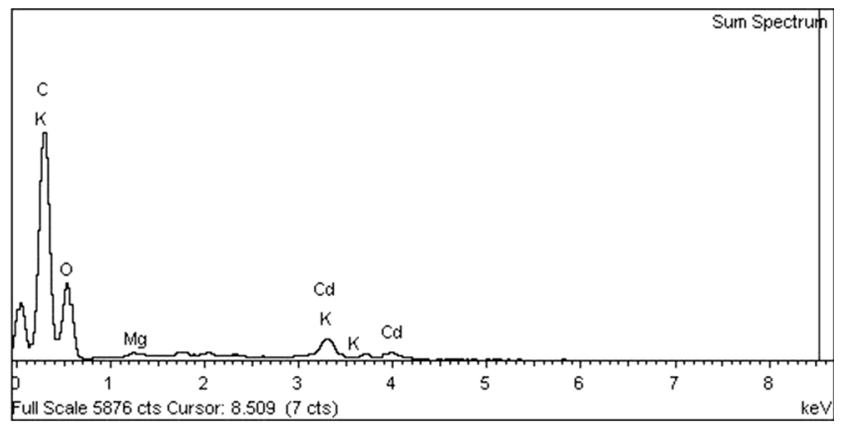

(f)

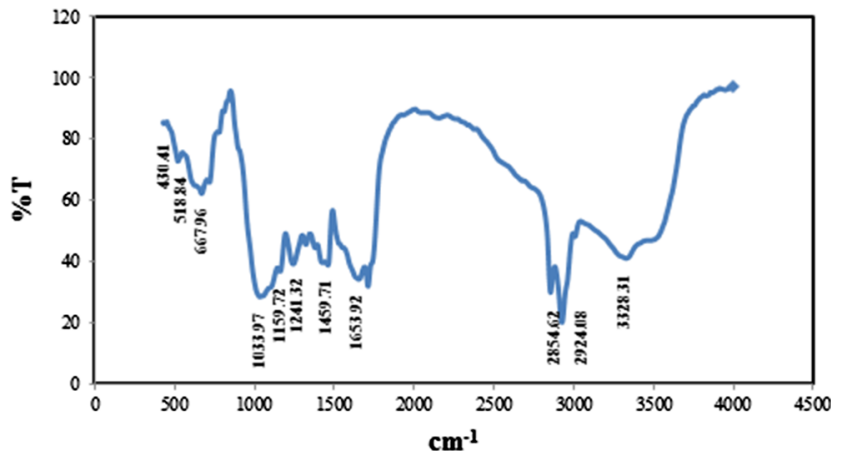

Fig. 1 SEM analysis of the biosorbent a before, b after Cd(II) adsorption (Cheraghi et al. 2015), EDX spectra $\mathbf{c}$ before, $\mathbf{d}$ after Cd(II), and adsorption FTIR spectra of biosorbent $\mathbf{e}$ before (Cheraghi et al. 2015), f after Cd(II) adsorption

stretching of phenols (Cheraghi et al. 2015). After the sesame was loaded with cadmium, some differences in the locations of the absorbance peaks were observed. Band shifting and the possible involvement of hydroxyl groups were found to be as the broad peak at $3298 \mathrm{~cm}^{-1}$ in the sorption process. In addition, there was a decrease in peak intensity at $3298 \mathrm{~cm}^{-1}$ according to the interaction between cadmium ions and different $\mathrm{O}-\mathrm{H}$ groups in the sesame. Moreover, the shift of the $\mathrm{C}-\mathrm{O}$ stretching vibration from 1054 to $1033 \mathrm{~cm}^{-1}$ clearly showed the interaction of cadmium with oxygen lone pair.

\section{Leaching test of biomass}

In order to investigate the effect of ions presented in the adsorption media, the leaching tests of the biomass were 


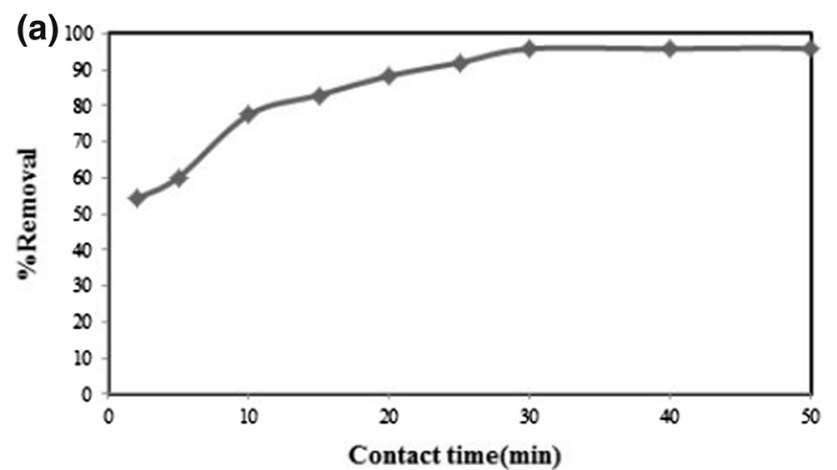

(b)

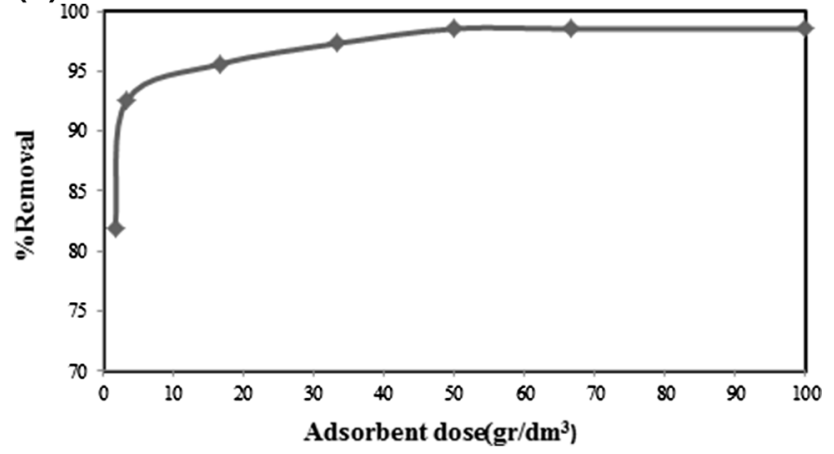

Fig. 2 Biosorption of $\mathrm{Cd}(\mathrm{II})$ from the solution with initial concentration $=20 \mathrm{mg} \mathrm{L}^{-1}$, agitation speed $=240 \mathrm{rpm}$ as a function of a time using adsorbent dose $=3.33 \mathrm{~g} \mathrm{dm}^{-3}, \mathrm{pH}=6$, b biosorbent dose, $\mathrm{pH} 5.5$

conducted in deionized water. The experiments were performed using an amount of $1 \mathrm{~g}$ of biomass, at $\mathrm{pH} 6$, for the shaking time of $50 \mathrm{~min}$. The filtrate solution was analyzed for the components leaching. The results are represented in Table 1. As can be seen, the concentrations of $\mathrm{K}(\mathrm{I}), \mathrm{Mg}(\mathrm{II})$ and $\mathrm{Ca}$ (II) were found to be $12.34,9.66$ and $19.12 \mathrm{mg} \mathrm{L}^{-1}$ in the aqueous solution (by using $1 \mathrm{~g}$ of biomass), respectively. From this data, one can conclude that penetration of $\mathrm{Mg}(\mathrm{II})$, $\mathrm{K}$ (II) and mainly $\mathrm{Ca}(\mathrm{II})$ ions to the solution showed the involvement of ion exchange mechanism in the cadmium ions removal by the sesame waste.

\section{Batch biosorption experiments}

\section{Equilibrium contact time and the adsorbent concentration}

Adsorption experiments were performed for different contact times, keeping all other experimental variables constant, viz. cadmium initial concentration of $20 \mathrm{ppm}$ and with a fixed adsorbent dose of $3.33 \mathrm{~g} \mathrm{dm}^{-3}$ at $\mathrm{pH}$ 5.5. The results are shown in Fig. 2a.

Adsorption of $\mathrm{Cd}$ (II) ions onto sesame was achieved after about $50 \mathrm{~min}$ of stirring time. There did not seem to be much benefit from an agitation time longer than $30 \mathrm{~min}$; thus, an equilibrium time of $30 \mathrm{~min}$ was considered for all
Table 1 Analysis of the filtrate solution for the components leaching from sesame waste, and adsorption-desorption data in consecutive cycles

\begin{tabular}{|c|c|c|c|c|c|}
\hline \multicolumn{6}{|c|}{ Metal ions concentration $\left(\mathrm{mg} \mathrm{L}^{-1}\right)$} \\
\hline \multicolumn{2}{|l|}{$\overline{\mathrm{K}^{+}}$} & \multicolumn{2}{|c|}{$\mathrm{Mg}^{2+}$} & \multicolumn{2}{|r|}{$\mathrm{Ca}^{2+}$} \\
\hline 12.34 & & & & & 19.12 \\
\hline \multirow[t]{2}{*}{ Cycle } & \multicolumn{3}{|l|}{ Adsorption } & \multicolumn{2}{|l|}{ Desorption } \\
\hline & $\begin{array}{l}C_{0} \\
\left(\mathrm{mg} \mathrm{L}^{-1}\right)\end{array}$ & $\begin{array}{l}C_{\mathrm{e}} \\
\left(\mathrm{mg} \mathrm{L}^{-1}\right)\end{array}$ & $\begin{array}{l}Q_{\mathrm{e}} \\
\left(\mathrm{mg} \mathrm{g}^{-1}\right)\end{array}$ & $\begin{array}{l}C_{\mathrm{f}} \\
\left(\mathrm{mg} \mathrm{L}^{-1}\right)\end{array}$ & $\begin{array}{l}\% \\
\text { Desorption }\end{array}$ \\
\hline 1 & 20 & 0.6 & 7.76 & 18.2 & 93.81 \\
\hline 2 & 20 & 6.65 & 5.34 & 11.2 & 83.89 \\
\hline 3 & 20 & 9.32 & 4.27 & 8.4 & 78.65 \\
\hline 4 & 20 & 11.3 & 3.48 & 6.3 & 72.41 \\
\hline
\end{tabular}

further studies. In addition, as can be seen in Fig. 2a, the removal rate was fast at the initial stage of the process time. The faster initial rate could be achieved according to the accessibility of the uncovered sorption sites of the sesame adsorbent at the beginning.

The dose of sorbents was varied from 1.67 to $100 \mathrm{~g} \mathrm{dm}^{-3}$. The effect of adsorbent dose on the percentage removal of $\mathrm{Cd}(\mathrm{II})$ ions is shown in Fig. $2 \mathrm{~b}$.

It may be perceived that by elevating the adsorbent dose, the percentage removal of $\mathrm{Cd}(\mathrm{II})$ ions was increased up to a adsorbent dose of $50 \mathrm{~g} \mathrm{dm}^{-3}$ and then remained constant. Growth in the percentage removal with adsorbent dose could be owing to the enhancement in the total mass transfer surface area and the availability of more adsorption sites. Moreover, reviewing the obtained results for the biosorption study revealed that there are many factors that testified the adsorbent dose effect. The essential one was that adsorption sites remained unsaturated through the adsorption reaction. The other reason could be attributed to the aggregation/agglomeration of sorbent particles at upper concentrations. Such aggregation would cause a reduction in the total mass transfer surface area of the sorbent particles presented for metal adsorption and an enhancement in the diffusional path length. Moreover, at high sorbent concentrations, the particle interaction could desorb some of the ions which were slackly and reversibly bound to the sorbent surface.

\section{Effect of particle size}

The effect of particle size on the removal of Cd(II) was investigated using some sesame having particle sizes ranging from 0.15 to $2 \mathrm{~mm}$, with a fixed adsorbent dose of $3.33 \mathrm{~g} \mathrm{dm}^{-3}$, the initial concentration of $20 \mathrm{ppm}$, and the $\mathrm{pH}$ of 5.5. It is obvious from Fig. 3 that the removal of $\mathrm{Cd}(\mathrm{II})$ progressed with a reduction in particle size, 


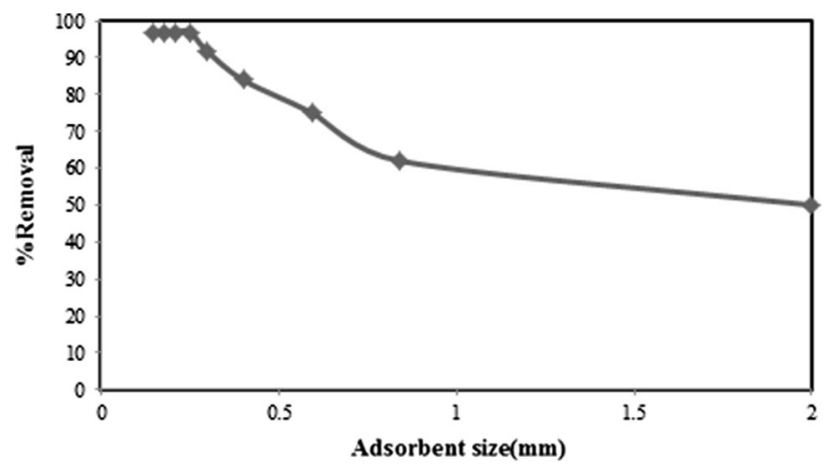

Fig. 3 Biosorption of $\mathrm{Cd}(\mathrm{II})$ onto the sesame using various mesh sizes of the biosorbent (initial metal concentration $=20 \mathrm{mg} \mathrm{L}^{-1}$, agitation speed $=240 \mathrm{rpm}$, adsorbent dose $=3.33 \mathrm{~g} \mathrm{dm}^{-3}, \mathrm{pH} 5.5$ )

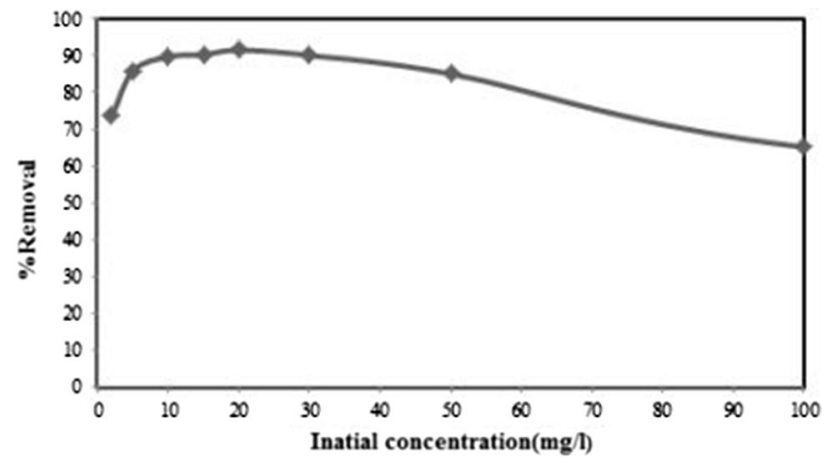

Fig. 4 Biosorption of $\mathrm{Cd}(\mathrm{II})$ on sesame at different initial metal concentrations (agitation speed $=240 \mathrm{rpm}, \quad$ adsorbent dose $=3.33 \mathrm{~g} \mathrm{dm}^{-3}, \mathrm{pH} 5.5$ )

probably due to the larger total mass transfer surface area available. Moreover, for sesame waste, milling to a particle size of $210 \mu \mathrm{m}$ seemed to be suitable for adsorption and all further studies on the adsorption of $\mathrm{Cd}(\mathrm{II})$ by the sesame biosorbent were carried out by maintaining the particle size of $210 \mu \mathrm{m}$.

\section{The effect of the initial metal ion concentration}

The effect of the initial concentration of $\mathrm{Cd}(\mathrm{II})$ on adsorption is shown in Fig. 4. The experiments were performed at $3.33 \mathrm{~g} \mathrm{dm}^{-3}$ adsorbent dose and the $\mathrm{pH}$ of 5.5. Figure 4 indicates that the removal was highly dependent on the initial concentration of the metal ions.

In general, the initial concentration provided the required driving force to overcome the mass transfer resistances of adsorbents between the aqueous and solid phases. The results also showed that the values of equilibrium adsorption were improved by increasing the initial concentration from 2 to $20 \mathrm{mg} \mathrm{L}^{-1}$. Moreover, at various initial ion concentrations ranging from 2 to $20 \mathrm{ppm}$, the enhancement in the initial concentration of metal ions increased the interaction between adsorbents and metal ions. Consequently, an increase in the initial concentration increased the adsorption uptake of metal ions. However, as can be seen in Fig. 4, in experiments with higher initial concentrations (up to $20 \mathrm{mg} \mathrm{L}^{-1}$ ), biosorption efficiencies were reduced with an increase in the initial metal concentrations. Similar results have been described by others (Garge et al. 2008). At lower metal concentrations, the ratio of the number of metal ions in aqueous solution to the available surface area was low; therefore, biosorption was not dependent on the initial concentration. At upper concentrations, the available sites for biosorption were less, and thus, metal removal was reliant on the initial concentration.

\section{The effect of $\mathrm{pH}$}

The $\mathrm{pH}$ value is considered as one of the main parameters controlling the sorption of metals with biosorbents. Adsorption experiments were performed in the $\mathrm{pH}$ range of 2-9, keeping all other parameters constant (cadmium concentration $=20 \mathrm{mg} \mathrm{L}^{-1}$; adsorbent dose $=3.33 \mathrm{~g} \mathrm{dm}^{-3}$ ). The effect of $\mathrm{pH}$ on the removal of $\mathrm{Cd}$ (II) from aqueous solutions is shown in Fig. 5a. As can be seen, the sorption capacity was clearly affected by the $\mathrm{pH}$.

The optimum $\mathrm{pH}$ value for the removal of $\mathrm{Cd}(\mathrm{II})$ was found to be 6 . The adsorption uptake of $\mathrm{Cd}(\mathrm{II})$ was enhanced from 33.45 to $92.95 \%$ with increasing $\mathrm{pH}$ value from 2 to 6 . After that, with increasing $\mathrm{pH}$ value up to 6 , the uptake of cadmium ions was decreased. The effect of $\mathrm{pH}$ on the biosorption capacity was related to the chemical form of heavy metals in the solution at a specific $\mathrm{pH}$, i.e., hydroxyl-metal form or pure ionic metal form. It is well known that the cadmium species in aqueous solutions are existent in the form of $\mathrm{Cd}^{2+}, \mathrm{Cd}(\mathrm{OH})^{+}, \mathrm{Cd}(\mathrm{OH})_{4}^{2-}$, $\mathrm{Cd}(\mathrm{OH})_{3-}, \mathrm{Cd}(\mathrm{OH})_{2(\mathrm{~S})}$, depending on the solution $\mathrm{pH}$. The concentration of the hydrolyzed cadmium species is related to the cadmium concentration and the solution $\mathrm{pH}$ (Garge et al. 2008).

$$
\begin{array}{ll}
\mathrm{Cd}(\mathrm{II})+\mathrm{H}_{2} \mathrm{O} \Leftrightarrow \mathrm{Cd}(\mathrm{OH})^{+}+\mathrm{H}^{+}, & \mathrm{pK}_{1}=7.9 \\
\mathrm{Cd}(\mathrm{OH})^{+}+\mathrm{H}_{2} \mathrm{O} \Leftrightarrow \mathrm{Cd}(\mathrm{OH})_{2}+\mathrm{H}^{+}, & \mathrm{pK}_{1}=10.6 \\
\mathrm{Cd}(\mathrm{OH})_{2}+\mathrm{H}_{2} \mathrm{O} \Leftrightarrow \mathrm{Cd}(\mathrm{OH})_{3}^{-}+\mathrm{H}^{+}, & \mathrm{pK}_{1}=14.3
\end{array}
$$

On the other hand, according to different functional groups on the biosorbent surface, which became active sites for the metal binding at a particular $\mathrm{pH}$, the effect of $\mathrm{pH}$ on biosorption could be significant. Hence, an enhancement in $\mathrm{pH}$ could result in a decrease or an increase in the biosorption capacity, thereby causing diverse optimum $\mathrm{pH}$ values related to the biosorbent type.

Moreover, the results could be explained based on the fact that the $\mathrm{pH}$ at point zero charge $\left(\mathrm{pH}_{\mathrm{pzc}}\right)$ of biosorbent might also affect the ionic state of the functional group 


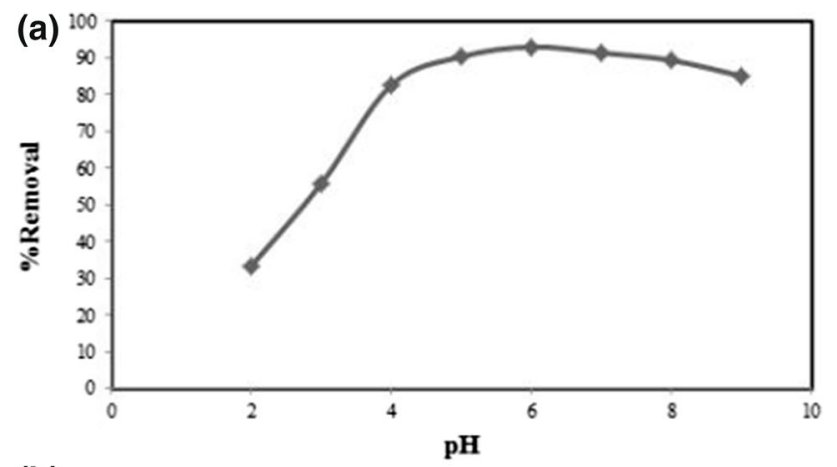

(b)

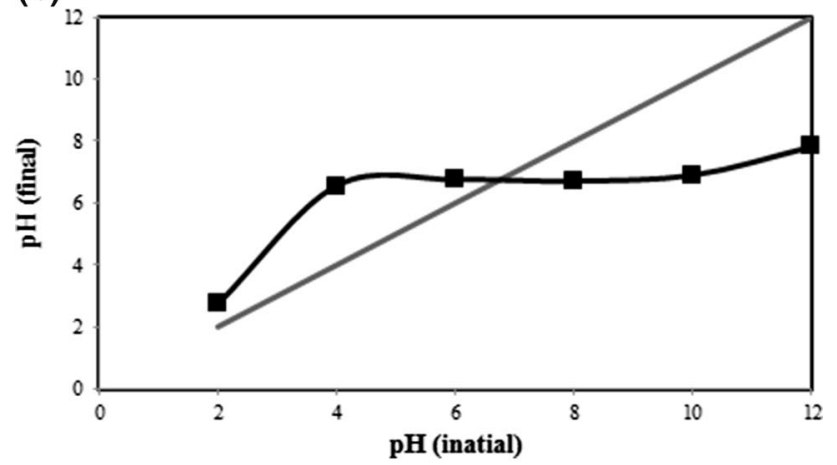

(c)

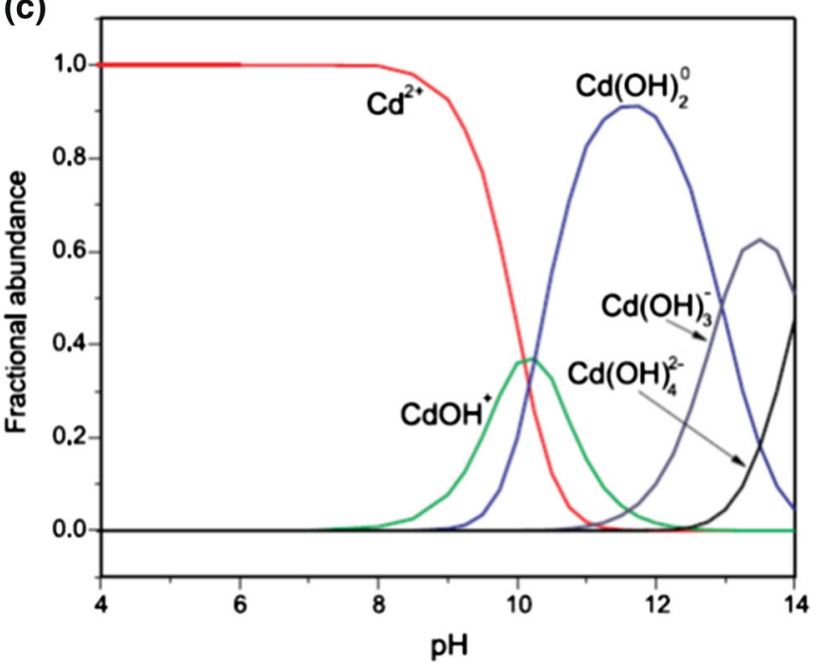

Fig. 5 a Biosorption of $\mathrm{Cd}(\mathrm{II})$ as a function of $\mathrm{pH}$ (initial metal concentration $=20 \mathrm{mg} \mathrm{L}^{-1}$, agitation speed $=240 \mathrm{rpm}$, adsorbent dose $=3.33 \mathrm{~g} \mathrm{dm}^{-3}$ ), b pHpzc curve of sesame waste, $\mathbf{c}$ species distribution of $\mathrm{Cd}(\mathrm{II})$ in pure water as a function of $\mathrm{pH}$ at $25^{\circ} \mathrm{C}$

existing on the adsorbent surface. As can be seen in Fig. 5b, the value of $\mathrm{pH}_{\mathrm{pzc}}$ of sesame was found to be 6.71 . Below this $\mathrm{pH}$ value, the surface charge of sesame was positive. Accordingly, the biosorbent surface was greatly protonated in acidic medium, which was not favorable for cadmium sorbent since in this medium, $\mathrm{Cd}(\mathrm{II})$ was the dominant ion (Huang and Ostovis 1978). As pH was enhanced, the degree of protonation of surface was decreased gradually and approached zero at $\mathrm{pH} 6.71$, resulting in a gradual increase in the adsorption. As can be seen in Fig. $5 \mathrm{c}$, above $\mathrm{pH} 7$, where $\mathrm{Cd}^{2+}$ and $\mathrm{Cd}(\mathrm{OH})^{+}$species were present in solution (Huang and Ostovis 1978; Ford et al. 2007), the degree of protonation of biosorbent surface was decreased and consequently generated a net negative charge making the situation electrostatically favorable for a higher cadmium uptake. However, as shown in Fig. 5c, above $\mathrm{pH} \mathrm{7,} \mathrm{the} \mathrm{removal} \mathrm{of} \mathrm{cadmium} \mathrm{started} \mathrm{to} \mathrm{reduce}$ according to soluble hydroxy complexes of cadmium hydroxides (Singh et al. 2005).

\section{Desorption and reusability of $C d(I I)$ ions}

The desorption studies help to describe the behavior of adsorption, the recovery of $\mathrm{Cd}$ (II) ions from aqueous solutions, the recycling of the adsorbent and practical applications of the treatment of industrial effluents. Desorption of adsorbed analyte ions onto sesame waste was studied using $\mathrm{HNO}_{3}$ at the concentration of $0.5 \mathrm{M}$. In the reusability tests, sorption was carried out for $\mathrm{Cd}$ (II) solution with an initial concentration of $20 \mathrm{mg} \mathrm{L}^{-1}$ by using $0.5 \mathrm{~g}$ of the biosorbent for $30 \mathrm{~min}$. Then the sesame waste was filtered, washed several times with deionized water and transferred to another $20 \mathrm{mg} \mathrm{L}^{-1} \mathrm{Cd}(\mathrm{II})$ solution. This process was repeated four times. Desorption experiments carried out with $\mathrm{Cd}(\mathrm{II})$ laden sesame waste showed that approximately $94 \%$ of the adsorbed cadmium was desorbed for the first cycle. The results showed that (Table 1) as the number of cycles that were attributed to the reutilization of the sesame waste was enhanced, the amount of the newly adsorbed $\mathrm{Cd}(\mathrm{II})$ was diminished. As shown in Table 1, nearly $80 \%$ of $\mathrm{Cd}(\mathrm{II})$ ions were able to be desorbed from sesame waste after the third cycle of desorption process. Moreover, the removal percentage of $\mathrm{Cd}(\mathrm{II})$ was found to be 97.0, 66.75, 53.4 and $43.5 \%$ for first, second, third and fourth cycle of the batch adsorption, respectively. This indicated that the test adsorbent could be reused without considerable losses in its initial adsorption capacity during desorption stages. Hence, sesame waste can be a sustainable and useful adsorbent for $\mathrm{Cd}$ (II) adsorption at commercial level. Similarly, Lunge et al. repeated adsorption-desorption cycles of As(III) five times by reusing the magnetic nanoparticles from the tea waste adsorbent. The reusability percentages for As(III) were 99.0, 84.0, 71.0, 60.0 and $49.0 \%$ for first, second, third, fourth and fifth cycle of adsorption, respectively. They concluded 
that this waste adsorbent could be used commercially for As(III) adsorption (Lunge et al. 2014).

\section{The adsorption isotherms}

In order to calculate the adsorption capacity of sesame waste, the experimental data were fitted to the Langmuir and Freundlich isotherm models. The Langmuir model assumes that the sorption of metal ions happens on a homogenous surface by monolayer adsorption with no interaction between adsorbed ions. The Langmuir and Freundlich models can be expressed as shown in Eqs. (12) and (13), respectively, below:

$Q_{\mathrm{e}}=\frac{Q_{\mathrm{max}} b C_{\mathrm{e}}}{\left(1+b C_{\mathrm{e}}\right)}$

where $Q_{\mathrm{e}}$ expresses the extent of metal adsorbed onto the biosorbent $\left(\mathrm{mg} \mathrm{g}^{-1}\right), C_{\mathrm{e}}$ is the equilibrium concentration of metal adsorbed in the solution $\left(\mathrm{mg} \mathrm{L}^{-1}\right), Q_{\max }$ represents the maximum adsorption capacity or the theoretical monolayer saturation capacity and $b$ is the Langmuir equilibrium constant.

$Q_{\mathrm{e}}=K_{\mathrm{F}} C_{\mathrm{e}}^{1 / n}$

For the Freundlich model, $K_{\mathrm{F}}\left(\mathrm{mg}^{1-1 / \mathrm{n}} \mathrm{L}^{1 / \mathrm{n}} \mathrm{g}^{-1}\right)$ is the constant associated with the adsorption capacity of the adsorbent, and $n$ (dimensionless) is the exponent associated with the adsorption intensity. The experimental data were fitted to both Langmuir and Freundlich isotherms (Fig. 6a, b) and the isotherm constants in Eqs. $(8,9)$. The regression coefficients $\left(R^{2}\right)$ are given in Table 2 .

Moreover, the essential characteristics of the Langmuir isotherm may be stated in terms of a dimensionless constant separation factor or equilibrium parameter (Weber and Chakraborti 1974) $R_{\mathrm{L}}$, which can be calculated by using the following equation:

$R_{L}=\frac{1}{\left(1+b C_{\mathrm{o}}\right)}$

The value of $R_{\mathrm{L}}(0.88)$ for the Cd(II) adsorption on sesame waste lying between 0 and 1 showed favorable adsorption (McKay et al. 1982). Therefore, the data represented a favorable adsorption for the adsorbent used in this study.

The Freundlich isotherm offered a fairly acceptable isotherm for non-ideal adsorption related to heterogeneous process. $1 / n$ value for $\mathrm{Cd}(\mathrm{II})$ lay between 0 and 1 , indicating favorable adsorption.

It was found that Langmuir model was best fitted to the experimental data with the coefficient of determination, $R^{2}$, being 0.99 as illustrated in Fig. 6a. This showed that sesame waste would provide the monolayer and homogeneous adsorption for the cadmium ions. (a)

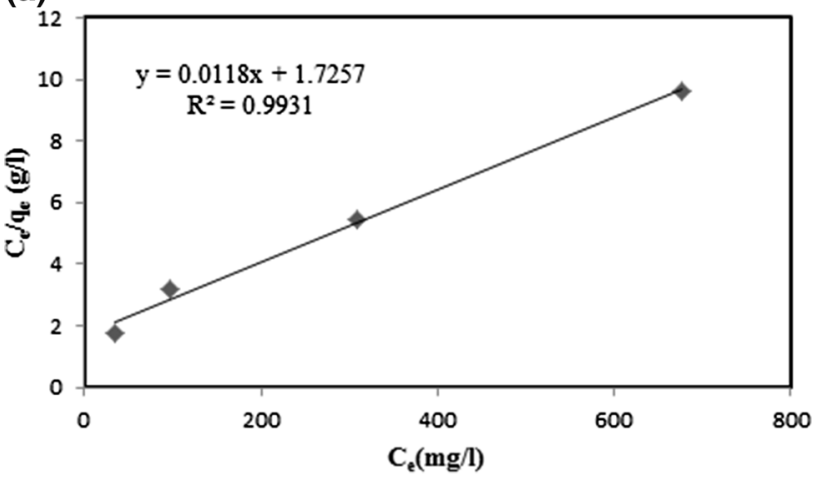

(b)

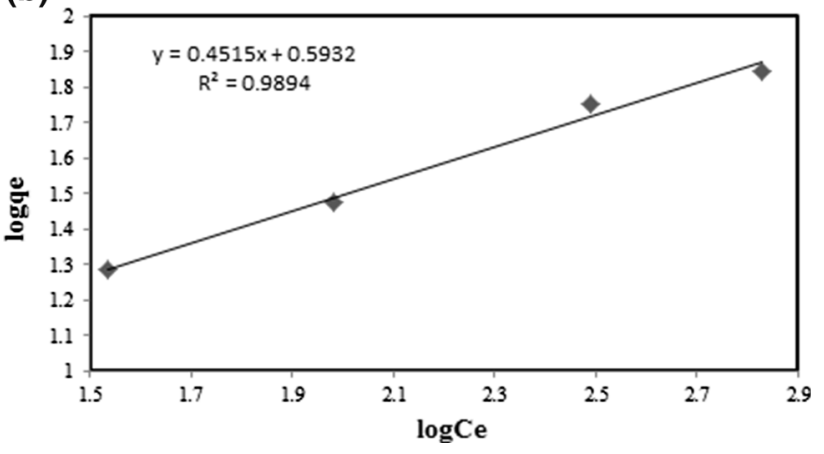

Fig. 6 Biosorption isotherms of Cd(II) based on a the Langmuir model and $\mathbf{b}$ the Freundlich model

Table 2 Langmuir and Freundlich isotherm constants for $\mathrm{Cd}(\mathrm{II})$ biosorption on sesame

\begin{tabular}{lccc}
\hline Langmuir isotherm & $Q_{\max }\left(\mathrm{mg} \mathrm{g}^{-1}\right)$ & $b\left(\mathrm{~L} \mathrm{mg}^{-1}\right)$ & $R^{2}$ \\
\hline Freundlich isotherm & $K_{\mathrm{f}}\left(\mathrm{L} \mathrm{g}^{-1}\right)$ & $1 / n$ & 0.0068 \\
\hline & 3.92 & 0.4525 & 0.98 \\
\hline
\end{tabular}

Biosorption kinetics

The rate at which sorption happens is of great importance when designing batch sorption experiments. Accordingly, it is essential to find the biosorption kinetics which can ensure the search for the best model that can well characterize the experimental data. Various sorption kinetic models have been used to describe the biosorption of metals. Two classical kinetic models, a pseudo-first-order kinetic model of Lagergren and a pseudo-second-order kinetic model of Ho, were applied to simulate the experimental data of $\mathrm{Cd}$ (II) on the sesame system. The pseudo-first-order equation, which is widely applied to predict metal sorption experiments, has the following form:

$\frac{\mathrm{d} Q}{\mathrm{~d} t}=k_{1}\left(Q_{\mathrm{e}}-Q_{t}\right)$ 
where $Q_{t}\left(\mathrm{mg} \mathrm{g}^{-1}\right)$ is the amount of metal ions biosorbed at time $t, Q_{\mathrm{e}}$ is the amount of metal ions biosorbed at equilibrium $\left(\mathrm{mg} \mathrm{g}^{-1}\right)$ and $\mathrm{k}_{1}$ is the rate constant of the biosorption $\left(\min ^{-1}\right)$. After definite integration by considering the conditions $Q_{t}=0$ at $t=0$ and $Q_{t}=Q_{t}$ at $t=t$, it is rewritten as the following equation,

$\ln \left(Q_{\mathrm{e}}-Q_{t}\right)=\ln Q_{\mathrm{e}}-k_{1} t$

The straight line in the graph of $\ln \left(Q_{\mathrm{e}}-Q_{t}\right)$ versus $t$ shows the applicability of this kinetic model, and $Q_{\mathrm{e}}$ and $k_{1}$ can be estimated with the values of $3.136 \mathrm{mmol} \mathrm{g}^{-1}$ and $0.0946 \mathrm{~min}^{-1}$ from the intercept and slope of the plot, respectively. The linear plot of $\ln \left(Q_{\mathrm{e}}-Q_{t}\right)$ versus t for the pseudo-first-order kinetic model is presented in Fig. 7a

The pseudo-second-order rate equation has been widely applied to explain metal ions and organic compounds sorption on diverse sorbents.

$\frac{\mathrm{d} Q}{\mathrm{~d} t}=k_{2}\left(Q_{\mathrm{e}}-Q_{t}\right)^{2}$

where $Q_{t}$ and $Q_{\mathrm{e}}\left(\mathrm{mg} \mathrm{g}^{-1}\right)$ are the extents of biosorption at time $t$ ( $\mathrm{min}$ ) and at equilibrium, respectively, and $k_{2}$ $\left(\mathrm{gm} \mathrm{g}^{-1} \mathrm{~min}^{-1}\right)$ is the rate constant of the second-order equation. After definite integration by using the conditions $Q_{t}=0$ at $t=0$ and $Q_{t}=Q_{t}$ at $t=t$, it is rewritten as the following equation,
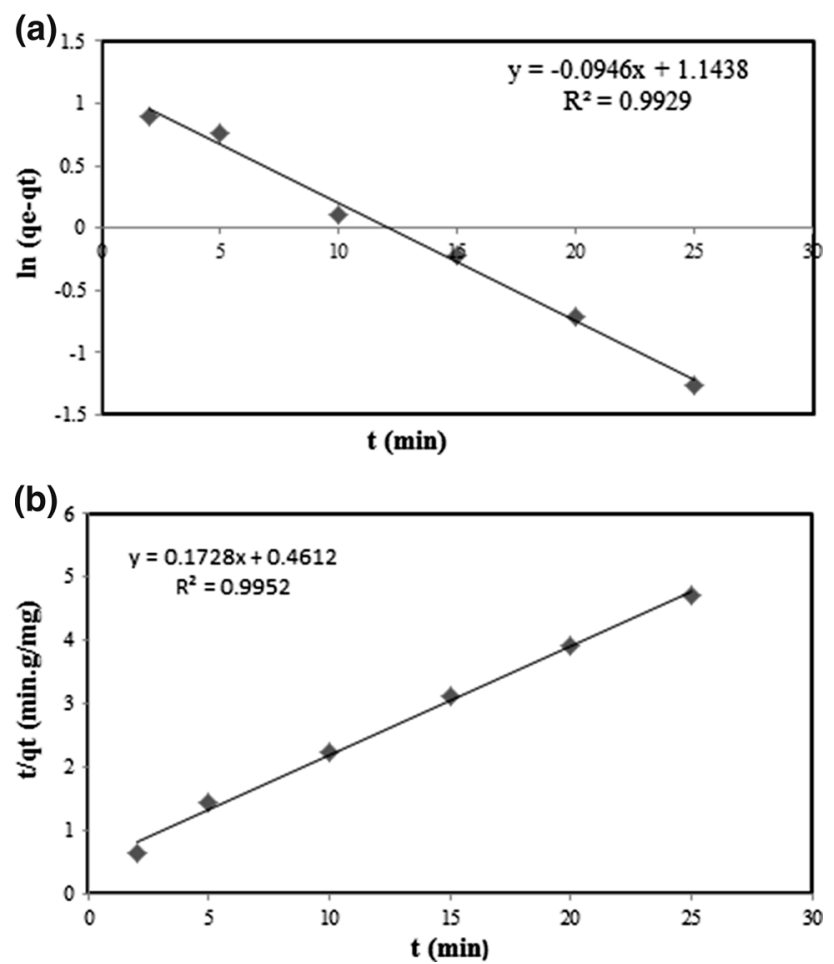

Fig. 7 Adsorption kinetics of Cd(II) based on a pseudo-first-order model and $\mathbf{b}$ pseudo-second-order model
$\frac{t}{Q_{t}}=\frac{1}{k_{2} Q_{\mathrm{e}}^{2}}+\frac{t}{Q_{\mathrm{e}}}$

The plot of $t / Q_{t}$ versus $\mathrm{t}$ should give a straight line if second-order kinetics is appropriate, and $Q_{\mathrm{e}}$ and $k_{2}$ can be estimated with the values of $5.787 \mathrm{mmol} \mathrm{g}^{-1}$ and $0.0647 \mathrm{~g} \mathrm{mg}^{-1} \mathrm{~min}^{-1}$ from the slope and intercept of the plot, respectively. The linear plot of $t / Q_{t}$ versus $t$ for the pseudo-second-order kinetic model is shown in Fig. $7 \mathrm{~b}$.

The values of correlation coefficients $(0.9952$ for pseudo-second-order and 0.9929 for first-order model) showed the better fit of pseudo-second-order model with the experimental data with respect to the Lagergren first-order model. Therefore, one could conclude that the rate limiting step was of chemisorption nature. Moreover, the proximity of the values of the correlation coefficients for the two kinetic models indicated that the adsorption process followed intra-particle diffusion model with more than one process affecting the adsorption process (Li et al. 2010).

The results of pseudo-second-order kinetics in this work are supported by the findings of some earlier studies (Aliabadi et al. 2006; Hossain et al. 2005).

\section{Continuous biosorption study}

The performance of the column bed is usually described by a breakthrough curve. The shape of the breakthrough curve and the time for breakthrough appearance are very significant characteristics for evaluating the operation and dynamic response of a sorption column (Ahmad and Hameed 2010; Han et al. 2009). The effluent concentration $\left(C_{t}\right)$ from the column arriving about $0.1 \%$ of the influent concentration $\left(C_{0}\right)$ is ordinarily called the breakthrough point. The point where the effluent concentration arrives at $95 \%$ is ordinarily called the exhaustion point (Kundu et al. 2004). The breakthrough obtained by plotting the measured concentration divided by the inlet concentration $\left(C_{t} / C_{0}\right)$ against time $(t)$ is used to realize the magnitudes of breakthrough and saturation time, biosorption yield (\%) and $\mathrm{Cd}(\mathrm{II})$ uptake parameters. The experimental breakthrough curve is shown in Fig. 8. The breakthrough time and exhaustion time were found to be 480 and $850 \mathrm{~min}$ in this study, respectively. In addition, other sorption column data such as the removal percentage of $\mathrm{Cd}(\mathrm{II})$ ions, the value of the total mass of metal adsorbed ( $\left.m_{\text {Total }}\right)$ and the maximum capacity of the column $\left(Q_{\text {Total }}\right)$ were evaluated to be $73.8 \%, 124$ and $91.54 \mathrm{mg}$, respectively.

As can be seen in Fig. 8, metal removal declines as a result of the progressive exhaustion of the binding sites. Moreover, the concentration profile of the effluent solution indicated that the adsorption zone, the part of the column where adsorbate was moved to the adsorbent, kept rising and finally coincided with the top of the column. The metal 


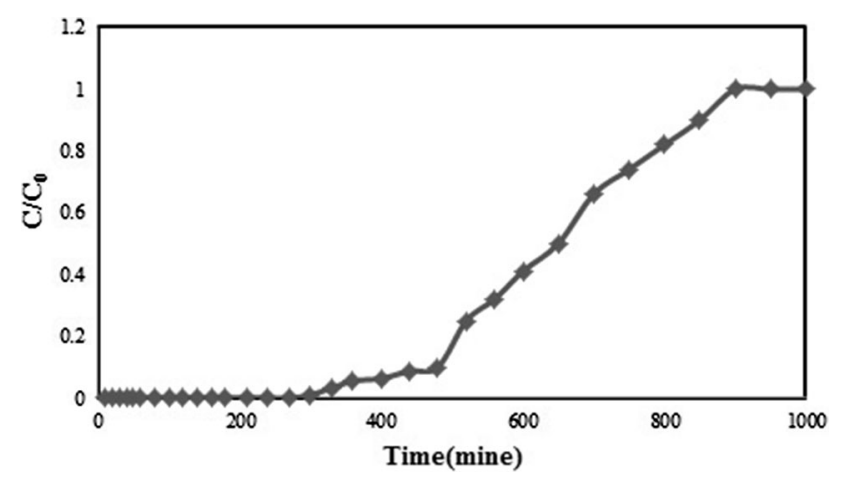

Fig. 8 Breakthrough curve of $\mathrm{Cd}(\mathrm{II})$ adsorption onto the sesame waste [the initial Cd(II) concentration of $60 \mathrm{mg} \mathrm{L}^{-1}$; the flow rate of $2.5 \mathrm{~mL} \mathrm{~min}^{-1}$; the bed height of $2 \mathrm{~cm}$; the $\mathrm{pH}$ of 5.5] (Cheraghi et al. 2015)

ion concentration was gradually increased, approaching the feed concentration (Sharma et al. 2009a, b).

The value of cadmium(II) uptake capacity of the biomass was found to be $22.88 \mathrm{mg} \mathrm{g}^{-1}$, which was very much comparable with other adsorbents (Cheraghi et al. 2015). For example, sphagnum peat moss, mollusk shells and macrofungus Pleurotus platypus were tested for $\mathrm{Cd}(\mathrm{II})$ ions removal by other scientists, and the uptake capacity of the biomasses was found to be $1.19,8.15$ and $13.25 \mathrm{mg} \mathrm{g}^{-1}$, respectively ( $\mathrm{Li}$ and Champagne 2009; Vimala et al. 2011). However, there may be biosorbents such as plain chitosan with higher cadmium uptake capacity (Saleh and Gupta 2014), but it is very important to consider the economic aspects through the biomass to form an appropriate biosorbent. As a result, it could be concluded that such useless biosorbent of sesame leaf used in this study had a reasonable sorption capacity, in contrast with other sorbents, with the additional advantage of being abundant and economic.

\section{Conclusion}

This study identified sesame waste as a useful material that can be utilized for the removal of $\mathrm{Cd}(\mathrm{II})$ ions from aqueous solutions. FTIR analysis of the biosorbent, before and after cadmium biosorption, revealed that carboxylic and hydroxyl groups could be the main functional groups involved in metal binding to the sesame waste. Adsorption equilibrium was attained within $30 \mathrm{~min}$. The adsorption process was found to follow both Lagergren first-order and pseudo-second-order kinetics models. However, the rate kinetics by the sesame waste biosorbent was best described by pseudo-second-order model. The equilibrium amount of metal ions removed by biosorption was increased with a decrease in the size of the biosorbent. The best results were obtained with $210-\mu \mathrm{m}$ biosorbent particle size. In addition, experimental results showed that the initial metal concentration and the dose of the biosorbent could have a dual effect on the biosorption process. The optimum initial metal concentration and the dose of the biosorbent values for the cadmium uptake were found to be $20 \mathrm{mg} \mathrm{L}^{-1}$ and $50 \mathrm{~g} \mathrm{dm}^{-3}$, respectively. The $\mathrm{pH}$ variation studies also indicated that the biosorption process for the sesame waste was highly $\mathrm{pH}$ dependent. The optimum $\mathrm{pH}$ value was found to be 6 . The adsorption isotherm investigations showed that Langmuir adsorption isotherm model fitted well with the experimental data. The maximum adsorption capacity $\left(Q_{\max }\right)$ was achieved $\left(84.74 \mathrm{mg} \mathrm{g}^{-1}\right)$. Moreover, desorption and reusability studies of the biomass sesame waste showed that it could be considered as a sustainable and useful adsorbent for $\mathrm{Cd}(\mathrm{II})$ adsorption at commercial level.

Acknowledgments The authors are thankful to Prof. H. Faghihian (Islamic Azad University, Shahreza Branch, Chemistry Faculty, Isfahan IRAN) for permitting and encouraging them to carry out the work.

\section{References}

Abdel Salam OE, Reiad NA, ElShafei MM (2011) A study of the removal characteristics of heavy metals from wastewater by lowcost adsorbents. J Adv Res 2:297-303

Ahmad AA, Hameed BH (2010) Fixed-bed adsorption of reactive azo dye onto granular activated carbon prepared from waste. J Hazard Mater 175:298-303

Ajmal M, Rao RAK, Ahmad R, Khan MA (2006) Adsorption studies on parthenium hysterophrous weed: removal and recovery of Cd(II) from wastewater. J Hazard Mater 135:242-248

Aliabadi M, Morshedzadeh K, Soheyli H (2006) Removal of chromium from aqueous solution by lignicellulosic solid wastes. Int J Environ Sci Technol 3:321-325

Aliabadi M, Khazaei I, Fakhraee H, Mousavian MTH (2012) Hexavalent chromium removal from aqueous solutions by using low-cost biological wastes: equilibrium and kinetic studies. Int J Environ Sci Technol 9:319-326

Allouche FN, Mamerid N, Guibal E (2011) Pb(II) biosorption on posidonia oceanica biomass. Chem Eng J 168:1174-1184

Al-Saadi AA, Saleh TA, Gupta VK (2013) Spectroscopic and computational evaluation of cadmium adsorption using activated carbon produced from rubber tires. J Mol Liq 188:136-142

Benaissa H (2006) Screening of new sorbent materials for cadmium removal from aqueous solutions. J Hazard Mater 132:189-195

Chang JS, Law R, Chang CC (1997) Biosorption of lead, copper and cadmium by biomass of pseudomonas aeruginosa PU21. Water Res 31:1651-1658

Cheraghi E, Ameri E, Moheb A (2015) Continuous biosorption of $\mathrm{Cd}(\mathrm{II})$ ions from aqueous solutions by sesame waste: thermodynamics and fixed-bed column studies. Desalin Water Treat. doi:10.1080/19443994.2015.1012744

Chowdhury Sh, Saha PD (2012) Scale-up of a dye adsorption process using chemically modified rice husk: optimization using response surface methodology. Desalin Water Treat 37:331-336

Dang VBH, Doan HD, Dang-Vu T, Lohi A (2009) Equilibrium and kinetics of biosorption of cadmium(II) and copper(II) ions by wheat straw. Bioresour Technol 100:211-219 
Dizadji N, Abootalebi Anaraki N (2011) Adsorption of chromium and copper in aqueous solutions using tea residue. Int J Environ Sci Tech 8:631-638

Feng N, Guo X, Liang S (2009) Adsorption study of copper(II) by chemically modified orange peel. J Hazard Mater 164:1286-1292

Ford RG, Wilkin RT, Puls RW (2007) Monitored natural attenuation of inorganic contaminants in ground water. US Environ Prot Agency 2:21-124

Garge U, Kaur MP, Jawa GKJ, Sud D, Garg VK (2008) Removal of cadmium(II) from aqueous solutions by adsorption on agricultural waste biomass. J Hazard Mater 154:1149-1157

Gupta VK, Nayak A (2012) Cadmium removal and recovery from aqueous solutions by novel adsorbents prepared from orange peel and $\mathrm{Fe}_{2} \mathrm{O}_{3}$ nanoparticles. Chem Eng J 180:81-90

Gupta VK, Saleh TA (2013) Sorption of pollutants by porous carbon, carbon nanotubes and fullerene-an overview. Environ Sci Pollut Res 20:2828-2843

Gupta VK, Agarwal S, Saleh TA (2011a) Chromium removal by combining the magnetic properties of iron oxide with adsorption properties of carbon nanotubes. Water Res 45:2207-2212

Gupta VK, Agarwal S, Saleh TA (2011b) Synthesis and characterization of alumina-coated carbon nanotubes and their application for lead removal. J Hazard Mater 185:17-23

Gupta VK, Jain R, Saleh TA, Nayak A (2011c) Equilibrium and thermodynamic studies on the removal and recovery of safranine- $\mathrm{T}$ dye from industrial effluents. Sep Sci Technol 46:839-846

Gupta VK, Kumar RV, Nayak A, Saleh TA, Barakat MA (2013) Adsorptive removal of dyes from aqueous solution onto carbonnanotubes: a review. Adv Colloid Interface Sci 193-194:24-34

Han R, Wang Y, Zhao X, Wang Y, Xie F, Cheng J, Tang M (2009) Adsorption of methylene blue by phoenix tree leaf powder in a fixed-bed column: experiments and prediction of breakthrough curves. Desalination 245:284-297

Han R, Zhang L, Song C, Zhang M, Zhu HM, Zhang L (2010) Characterization of modified wheat straw, kinetic and equilibrium study about copper ion and methylene blue adsorption in batch mode. Carbohydr Polym 79:1140-1149

Hossain MA, Kumita M, Michigami Y, Mori S (2005) Kinetics of $\mathrm{Cr}(\mathrm{VI})$ adsorption on used black tea leaves. J Chem Eng Jpn 38:402-408

Hou XX, Deng QF, Ren TZ, Yuan ZY (2013) Adsorption of $\mathrm{Cu}^{2+}$ and methyl orange from aqueous solutions by activated carbons of corncob-derived char wastes. Environ Sci Pollut Res 20:8521-8534

Huang CP, Ostovis FB (1978) Removal of cadmium(II) by activated carbon adsorption. J Environ Eng 104:863-878

Ibrahim MNM, Wan Ngaha WS, Norliyanaa MS, Wan Daudb WR, Rafatullahb M, Sulaimanb O, Hashimb R (2010) A novel agricultural waste adsorbent for the removal of leadII) ions from aqueous solutions. J Hazard Mater 182:377-385

Kadirvelu K, Namasivayam C, Thamaraiselve K (2001) Removal of heavy metal from industrial wastewaters by adsorption on to activated carbon prepared from an agricultural solid waste. Bioresour Technol 76:63-65

Kamsonlian S, Suresh S, Ramanaiah V, Majumder CB, Chand S, Kumar A (2012) Biosorptive behaviour of mango leaf powder and rice husk for arsenic(III) from aqueous solutions. Int $\mathrm{J}$ Environ Sci Technol 9:565-578

Kannan N, Rengasamy G (2005) Comparison of Cd adsorption on various activated carbon. Water Air Soil Pollut 163:185-201

Kumar U, Bandyopadhyay M (2006) Sorption of Cd from aqueous solution using pretreated rice husk. Bioresour Technol 97:104-109
Kundu S, Kavalakatt SS, Pal A, Ghosh SK, Mandal M, Pal T (2004) Removal of arsenic using hardened paste of Portland cement: batch adsorption and column study. Water Res 38:3780-3790

Kurniawan TA, Chan GYS, Lo WH, Babel S (2006) Comparison of low-cost adsorbents for treating wastewater laden with heavy metals. Sci Total Environ 366:409-426

Li C, Champagne P (2009) Fixed-bed column study for the removal of cadmium(II) and nickel(II) ions from aqueous solutions using peat and mollusk shells. J Hazard Mater 71:872-878

Li L, Liu S, Zhu T (2010) Application of activated carbon derived from scrap tires for adsorption of rhodamine B. J Environ Sci 22:1273-1280

Lunge S, Singh S, Sinha A (2014) Magnetic iron oxide $\left(\mathrm{Fe}_{3} \mathrm{O}_{4}\right)$ nanoparticles from tea waste for arsenic removal. J Magn Magn Mater 356:21-31

McKay G, Blair HS, Gardener JR (1982) Adsorption of dyes on chitin. I. Equilibrium studies. J Appl Polym Sci 27:3043-3057

Mohanty K, Jha M, Meikap BC, Biswas MN (2006) Biosorption of $\mathrm{Cr}(\mathrm{VI})$ from aqueous solutions by eichhornia crassipes. J Chem Eng 117:71-77

Montanher SF, Oliveira EA, Rollemberg MC (2005) Removal of metal ions from aqueous solutions by sorption onto rice bran. J Hazard Mater B 117:207-211

Namasivayam C, Kavitha D (2006) IR, XRD and SEM studies on the mechanism of adsorption of dyes and phenols by coir pith carbon from aqueous phase. Microchem J 82:43-48

Nameni M, Alavi Moghadam MR, Arami M (2008) Adsorption of hexavalent chromium from aqueous solutions by wheat bran. Int J Environ Sci Tech 5:161-168

Nassar NN (2010) Rapid removal and recovery of $\mathrm{Pb}(\mathrm{II})$ from wastewater by magnetic nanoadsorbents. J Hazard Mater 184:538-546

Oguz E, Ersoy M (2010) Removal of $\mathrm{Cu}^{2+}$ from aqueous solution by adsorption in a fixed bed column and neural network modeling. Chem Eng J 164:56-62

Saleh TA (2011) The influence of treatment temperature on the acidity of MWCNT oxidized by $\mathrm{HNO}_{3}$ or a mixture of $\mathrm{HNO}_{3} /$ $\mathrm{H}_{2} \mathrm{SO}_{4}$. Appl Surf Sci 257:7746-7751

Saleh TA, Gupta VK (2012) Photo-catalyzed degradation of hazardous dye methyl orange by use of a composite catalyst consisting of multi-walled carbon nanotubes and titanium dioxide. J Colloid Interface Sci 371:101-106

Saleh TA, Gupta VK (2014) Processing methods, characteristics and adsorption behavior of tire derived carbons: a review. Adv Colloid Interface Sci 211:93-101

Saleh TA, Agarwal S, Gupta VK (2011) Synthesis of MWCNT/MnO and their application for simultaneous oxidation of arsenite and sorption of arsenate. Appl Catal B 106:46-53

Sari A, Tuzen M (2009) Kinetic and equilibrium studies of $\mathrm{Pb}(\mathrm{II})$ and Cd(II) removal from aqueous solution onto colemanite ore waste. Desalination 249:260-266

Sharma N, Kaur K, Kaur S (2009a) Kinetic and equilibrium studies on the removal of $\mathrm{Cd}^{2+}$ ions from water using polyacrylamide grafted rice (Oryza sativa) husk and (Tectona grandis) saw dust. J Hazard Mater 163:1338-1344

Sharma YC, Srivastava V, Weng CH, Upadhyay SN (2009b) Removal of $\mathrm{Cr}(\mathrm{VI})$ from wastewater by adsorption on iron nanoparticles. Can J Chem Eng 87:921-929

Shukla A, Zhang YH, Dubey P, Margrave JL, Shukla SS (2002) The role of sawdust in the removal of unwanted materials from water. J Hazard Mater 95:137-152

Singh KK, Rastogi R, Hasan SH (2005) Removal of cadmium from waste water using agricultural waste using rice polish. J Hazard Mater 121:51-58 
Surchi KMS (2011) Agricultural wastes as low cost adsorbents for $\mathrm{Pb}$ removal: kinetics, equilibrium and thermodynamic. Int $\mathrm{J}$ Chem 3:103-112

Tunali S, Akar T, Ozcan AS, Kiran I, Ozcan A (2006) Equilibrium and kinetics of biosorption of lead(II) from aqueous solutions by Cephalosporium aphidicola. Sep Purif Technol 47:105-112

Vilar VJP, Botelho CMS, Boaventura RAR (2006) Equilibrium and kinetics modeling of $\mathrm{Cd}(\mathrm{II})$ biosorption by algae Gelidium and agar extraction algal waste. Water Res 40:291-302
Vimala R, Charumathi D, Nilanjana D (2011) Packed bed column studies on $\mathrm{Cd}(\mathrm{II})$ removal from industrial wastewater by macrofungus Pleurotus platypus. Desalination 275:291-296

Volesky B, May H, Holan ZR (1993) Cadmium biosorption by saccharomyces cerevisiae. Biotechnol Bioeng 41:826-829

Weber TW, Chakraborti RK (1974) Pore and solid diffusion models for fixed bed adsorbents. AIChE J 20:228-238 